\title{
Etiolation and flooding of donor plants enhance the capability of Arabidopsis explants to root
}

\author{
Mehdi Massoumi ${ }^{1,2}$ - Frans A. Krens ${ }^{1} \cdot$ Richard G. F. Visser $^{1}$. \\ Geert-Jan M. De Klerk ${ }^{1}$
}

Received: 26 February 2017 / Accepted: 28 May 2017 / Published online: 2 June 2017

(C) The Author(s) 2017. This article is an open access publication

\begin{abstract}
Rooting of cuttings depends not only on the rooting treatment and the genotype, but also on the condition of the cuttings at the time of excision. The physiological and developmental conditions of the donor plant may be decisive. We have examined in Arabidopsis the effect of two donor plant pre-treatments, etiolation and flooding, on the capability of flower stem and hypocotyl segments to root. For etiolation, plantlets were kept in the dark, hypocotyls up to 12 days and plantlets for 12 weeks. Flooding was applied as a layer of liquid medium on top of the semisolid medium. This procedure is also referred to as "double layer". Both pre-treatments strongly promoted rooting and we examined possible mechanisms. Expression of strigolactone biosynthesis and signaling related genes indicated that promotion by etiolation may be related to enhanced polar auxin transport. Increased rooting after flooding may have been brought about by accumulation of ethylene in the cutting (ethylene has been reported to increase sensitivity to auxin) and by massive formation of secondary phloem (the tissue close to which adventitious roots are induced). Both pre-treatments also strongly lowered the endogenous
\end{abstract}

Communicated by Sergio J. Ochatt.

Electronic supplementary material The online version of this article (doi:10.1007/s11240-017-1244-1) contains supplementary material, which is available to authorized users.

Mehdi Massoumi

mehdi.massoumi@yahoo.com; mehdi.massoumi@eurotiss.nl

1 Wageningen U\&R Plant Breeding, Wageningen University and Research, P. O. Box 386, 6700 AJ Wageningen, The Netherlands

2 Euro-Tiss Company, Laageinde 6, 4016 CV Kapel Avezaath Buren, The Netherlands sucrose level. As low sucrose favors the juvenile state and juvenile tissues have a higher capability to root, the low sucrose levels may also play a role.

Keywords Adventitious root formation - Arabidopsis thaliana $\cdot$ Donor plant pre-treatment $\cdot$ Etiolation $\cdot$ Flooding

\section{Introduction}

Vegetative propagation is the predominant propagation method in horticulture and forestry and various major agricultural crops (Hartmann et al. 2011). Since cuttings that are excised from the donor plants obviously have no roots, adventitious root (AR) formation is indispensable in vegetative propagation (De Klerk et al. 1999b). Treatment with auxin is the common way to induce ARs (De Klerk et al. 1999a), but a significant number of crops is recalcitrant to this treatment. Despite much research, no other general applicable rooting treatments have been developed. An alternative way to increase rooting is donor plant pretreatment aiming at cuttings with an increased capability to respond to auxin. In this context, we have previously examined rejuvenation of donor plants (Massoumi et al. 2017). In the present paper, we deal with etiolation and with flooding, the other two rooting promoting pre-treatments (De Klerk 2002).

When applied during the rooting treatment, light (quality, intensity and duration) often influences the rooting of cuttings (e.g., Daud et al. 2013). Studies on the effect of light on rooting have provided evidence both for possible synergistic and antagonistic interactions of light with plant growth regulators e.g., auxin and cytokinins (CKs) (FettNeto et al. 2001; Wynne and McDonald 2002). 
Light changes also rootability of cuttings when the donor plant has been treated. Keeping donor plants for some period (weeks) in the dark, a pre-treatment usually referred to as etiolation, often improves the rootability of cuttings (Hammerschlag et al. 1987; Klopotek et al. 2010; Koukourikou-Petridou 1998; Shi and Brewbaker 2006). Researchers have attempted to relate the stimulation by etiolation with anatomical, physiological and molecular changes (Maynard and Bassuk 1988; Haissig and Davis 1994; Hartmann et al. 2011; Sorin et al. 2005) but the mechanism is still not understood. A complicating factor is the plural role of sucrose, the product of photosynthesis: energy source, building block and signal molecule. With respect to plant hormones, it was initially believed that brassinosteroids play a key role in etiolation but this has been refuted. It has been suggested that gibberellin $\left(\mathrm{GA}_{1}\right)$ plays such role: after exposure of deetiolated seedlings to light, there is an inhibition of stem growth caused in part by a rapid drop in $\mathrm{GA}_{1}$ (reviewed in Symons and Reid 2003). There are various reports on the effect of etiolation on changing endogenous indole3 -acetic acid (IAA) in cuttings. An increased IAA level has been reported in etiolated stem parts of eucalyptus (Fett-Neto et al. 2001), carnation (Agulló-Antón et al. 2011) and pea (Koukourikou-Petridou 1998). Additionally, light would affect the level of endogenous auxin either by influencing its transport or its metabolism into conjugates or via photo-oxidation (Ding et al. 2011; Normanly et al. 2004; Sassi et al. 2012). There are few reports about the influence of light on auxin signaling. It has been reported that light has a contrasting effect on the expression of AUXIN RESPONSE FACTOR (ARF) genes. While it positively affects expression of $A R F 6$ and $A R F 8$ (both positive controllers of AR initiation), it negatively regulates expression of $A R F 17$ (negative controller of $\mathrm{AR}$ initiation) (Gutierrez et al. 2009). Auxin signaling happens through the $\mathrm{SCF}^{\mathrm{TIR} 1}$-Aux/IAA-ARF pathway. In Arabidopsis TIR1 (TRANSPORT INHIBITOR RESISTANT 1) and AFBs [AUXIN SIGNALING F-BOX PROTEIN 1 through 5 (AFB1-5)] are F-box components of a nuclear SCF-type E3 ubiquitin ligase, which target the Aux/IAA (AUXIN/INDOLE-3-ACETIC ACID INDUCIBLE) proteins for degradation (Gray et al. 2001; Petroski and Deshaies 2005; dos Santos Maraschin et al. 2009). Whether light influences auxin signaling via change in expression of TIRI and AFBS is not clear.

In the present research, we studied mechanisms underlying the effect of etiolation, a donor plant pre-treatment, on AR formation of Arabidopsis explants cultured in vitro. We mainly focused on the changes in endogenous sugar level as well as in expression of auxin signaling and strigolactone (SL) biosynthesis/signaling related genes as caused by etiolation.
Apart from rejuvenation and etiolation, flooding also has been reported to enhance rootability (Voesenek and Sasidharan 2013). This is mediated by an accumulation of endogenous ethylene brought about by a reduction in gas release from submerged tissue (Vidoz et al. 2010; Visser et al. 1996). It should be noted that the diffusion rate of gases in water is 10,000 times slower than in air (Jackson 1985). Roots are most prone to flooding and the first to suffer from oxygen shortage. Several mechanisms have been described that help maintain root function through an improved oxygen supply during flooding. Establishment of a lateral diffusion barrier (Bramley et al. 2010), formation of internal gas spaces (aerenchyma) (Colmer and Voesenek 2009) as well as initiating organogenesis to replace the original root system with ARs roots are those which have been thoroughly addressed (Maurenza et al. 2012; Zhou et al. 2012).

In addition to the positive influence of flooding on AR formation potential while the root system is still connected, flooding has also been reported to pose similar effects on cuttings. Shibuya et al. (2013, 2014) reported that soaking the basal cuttings of Carolina poplar (Populus canadensis Moench.) and Japanese cedar (Cryptomeria japonica D. Don) in warmed water at controlled low-air-temperature improves early initiation and development of ARs. However, it seems that the better rooting response of cuttings treated with warm water is because of temperature gradient created by warm water at their basal portion while cooling their apical ends.

Double layer (a layer of liquid medium on top of the semi-solid medium) is the tissue culture equivalent of flooding. The effect of double layer on rooting has been examined occasionally and a strong increase was observed (De Klerk 2002; Maene and Debergh 1985). In the present study, we investigated the effect of flooding/double layer culture as another donor plant pre-treatment on rootability of Arabidopsis explants cultured in vitro. Understanding its underlying mechanisms may help application of this technique to improve in vitro rooting of other plant species at commercial scale.

\section{Materials and methods}

\section{Plant materials}

Arabidopsis thaliana (Col-0) seeds (Lehle Seeds, Round Rock, USA) were surface-sterilized with $70 \%$ (v/v) ethanol for one minute followed by $2 \%(\mathrm{w} / \mathrm{v})$ sodium hypochlorite for $10 \mathrm{~min}$. Then the seeds were rinsed three times for 10 min with sterile distilled water. They were germinated in Petri dishes up to the seedling stage (for hypocotyl explants) or containers up to flowering plants (for flower 
stem explants) using half-strength MS (MS1/2) basal salt mixture including vitamins (Murashige and Skoog 1962), 3\% (w/v) sucrose and 0.7\% (w/v) Micro-agar (Duchefa, Netherlands). To synchronize germination, the seeds were first stratified in the dark for 3 days at $4{ }^{\circ} \mathrm{C}$. Then they were transferred to $20^{\circ} \mathrm{C}$ under long day ( $16 \mathrm{~h}$ light $/ 8 \mathrm{~h}$ dark) conditions $\left(30 \mu \mathrm{mol} \mathrm{m}^{-2} \mathrm{~s}^{-1}\right.$, Philips TL33).

\section{Etiolation}

We kept the Petri dishes containing seeds vertically. The seedlings did grow alongside the medium surface. They were grown for $12,9,6,3$ or 0 days in the dark followed by $0,3,6,9$, or 12 days respectively in the light. The light con-

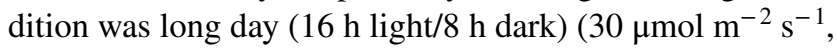
Philips TL33). After that, 5-10 mm-long hypocotyl segments were taken and their rooting responses were evaluated.

For flower stem (FS) explants, seedlings were germinated and grown in the darkness for 12 weeks in plastic containers. As control, plantlets were cultured in the light (same light conditions as hypocotyls). The rooting responses of 5-7 mm-long FS segments were compared.

\section{Flooding}

For hypocotyl explants, seeds were first germinated up to seedlings in darkness for $6 \mathrm{~d}$ in plastic containers $(68 \times 66 \mathrm{~mm})$. Darkness was used to elongate the hypocotyls as they are otherwise very short and difficult to work with. The flooding treatment (a layer of liquid half-strength MS medium ( $25 \mathrm{ml}$ equal to 6-7 $\mathrm{mm}$ ) on top of the semisolid MS1/2 medium) was applied in the light and lasted 1 week. After that, $10 \mathrm{~mm}$-long hypocotyl segments were excised and used for rooting.

For FS explants, after 4 weeks, when the donor plants were fully developed in plastic containers $(90 \times 80 \mathrm{~mm})$, flooding treatment ( $40 \mathrm{ml}$ equal to 6-7 $\mathrm{mm}$ ) was applied for 1 week. Then the rooting of 5-7 mm-long explants excised from FSs of flooded and control plants was evaluated.

\section{Rooting treatment}

Rooting responses of explants [hypocotyl or FS (nodefree sections)] excised from etiolated or flooded donor plants were compared with their nontreated (control) counterparts. We examined the rooting response according to Massoumi and De Klerk (2013). The authors showed that different explants respond differently to the applied auxins. For example, they showed that indole3-butyric acid (IBA) and indole-3-acetic acid (IAA) are the auxins of choice for rooting of hypocotyl and FS explants, respectively. Therefore, in the current study, we applied IBA $(10 \mu \mathrm{M})$ and IAA $(30 \mu \mathrm{M})$ for rooting of hypocotyl and FS explants, respectively. The selected concentrations are also based on the findings of Massoumi and De Klerk (2013). Considering that IAA and IBA are sensitive to photo-oxidation (although IBA to a lesser extent) and auxins are only required during the first few days after explant excision (De Klerk et al. 1989), the cultures were kept in darkness during rooting treatment for 1 week to avoid the photo-oxidation of applied auxins and after that the explants were transferred into hormone-

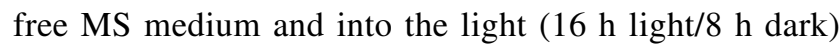

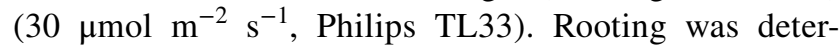
mined at the indicated times ( 12 and 21 days after culture establishment for hypocotyl and for FS explants, respectively) as percentage of rooted explants and as mean number of roots per explant. For each determination, 30 explants were used.

\section{Histological analysis}

FS segments of flooded and control Arabidopsis plants were fixed in $5 \%(\mathrm{v} / \mathrm{v})$ glutaraldehyde solution in $0.1 \mathrm{M}$ phosphate buffer ( $\mathrm{pH}$ 7.2) for $2 \mathrm{~h}$ at room temperature. Plant materials were then rinsed four times (15 min each) in $0.1 \mathrm{M}$ phosphate buffer ( $\mathrm{pH}$ 7.2) followed by four times (15 min each) rinsing in demi-water. Then the materials were dehydrated in a gradient series of ethanol (v/v: 10 , 30 and $50 \%$ each for $15 \mathrm{~min}, 70,90 \%$ and absolute ethanol for $2 \mathrm{~h}$ each step) before processing further with glycol-methacrylate-based resin (Technovit 7100, HeraeusKulzer Technik, Germany). Infiltration in Technovit was performed according to the manufacturer's instruction. Sections $(5 \mu \mathrm{m}$ thick) were cut with a rotary microtome, mounted onto glass slides, dried on a heater $\left(60^{\circ} \mathrm{C}\right)$ and stained with $0.25 \%(\mathrm{w} / \mathrm{v})$ toluidine blue in distilled water.

\section{Soluble sugars}

Hypocotyls and FSs were dried at $68^{\circ} \mathrm{C}$ for 2-3 days and ground with mortar and pistil. Hot ethanol was used to extract soluble sugars. For each condition, five samples of hundred explants were extracted three times with $5 \mathrm{ml}$ $80 \%(\mathrm{v} / \mathrm{v})$ ethanol, by boiling the samples in glass tubes capped with glass marbles in a $95^{\circ} \mathrm{C}$ water bath for $10 \mathrm{~min}$ each. After each extraction, the tubes were centrifuged at $2500 \mathrm{rpm}$ for $5 \mathrm{~min}$, the supernatants of the three extractions were combined for sugar analysis and evaporated to dryness. Soluble sugars were determined by the Anthrone method (Yemm and Willis 1954). Absorption was measured at $620 \mathrm{~nm}$ with a Beckman DU-50 Spectrophotometer. A standard curve was made with sucrose. 


\section{Quantitative real-time PCR}

Per treatment 200 hypocotyls were harvested, pooled and ground to fine powder in liquid nitrogen. Total RNA was extracted using an RNeasy Plant Mini Kit (Qiagen, Valencia, CA, USA) and subjected to a treatment with RNasefree DNase I (Qiagen) following the manufacturer's instructions. The extracted RNA served as template for the synthesis of single-stranded cDNA templates with the QuantiTect Reverse Transcription Kit (Qiagen, Valencia, CA, USA) according to manufacturer's instructions. Quantitative Real-Time PCR (qRT-PCR) was performed using the SYBR Green Supermix with a CFX96 Real-Time PCR Detection System (Bio-Rad Laboratories, Hercules, CA, USA). All qRT-PCR assays were performed as follows: $95^{\circ} \mathrm{C}$ for $3 \mathrm{~min}, 40$ cycles of $95^{\circ} \mathrm{C}$ for $10 \mathrm{~s}, 55^{\circ} \mathrm{C}$ for $30 \mathrm{~s}$. At the end of the PCR, the temperature was increased from 55 to $95^{\circ} \mathrm{C}$ to generate the melting curve. The expression of the following genes was measured: more axillary growth 1 through 4 (MAX1: At2g26170; MAX2: At2g42620; MAX3: At2g44990; MAX4: At4g32810), auxin signaling F-boxl and 2 (AFB1: At4g03190; AFB2: At3g26810) and transport inhibitor response 1 (TIR1: At3g62980). The primer pairs used for qRT-PCR are shown in Supplementary Table S1. The relative changes in gene expression were calculated by the $2^{-\Delta \Delta C_{t}}$ method (Livak and Schmittgen 2001); the expression levels of genes of interest were normalized to the expression level of the gene actin-2 (ACT2: At3g 18780). Each value is the mean $\pm \mathrm{SE}$ of three biological and three technical replicates and presents the ratio of expression in the light divided by expression in the dark.

\section{Statistics}

For all rooting experiments, three repeats each containing 10 explants were used in each treatment. Statistical analysis was done using Microsoft Excel 2013. The means \pm SE are given in the graphs. The significance of difference between root numbers was determined with a Student $t$ test and between the percentages with a $\chi^{2}$ - test. All experiments were carried out at least twice.

\section{Results}

\section{Etiolated donor plants}

\section{Morphology}

Dark and light grown seedlings showed the expected morphological differences. Seedlings that had grown in continuous darkness developed very long hypocotyls $(\sim 30 \mathrm{~mm})$. The length of hypocotyls decreased with the number of days in the light, and the shortest hypocotyls $(\sim 5 \mathrm{~mm})$ occurred in continuous (12 days) light. In addition, seedlings that had grown in total darkness were white. The chlorophyll content increased with the number of days of exposure to the light. At the end of the pre-treatment period (12 days), in some hypocotyls root initials were visible.

Similar results were obtained with FS segments. We germinated seeds and grew them for 12 weeks in the dark. The dark grown plants were etiolated (white and strongly elongated). In addition, compared to light-grown donor plants (control) that have a single FS and few lateral branches, massive production of axillary branches occurred. Flower stem's leaves were abnormally developed compared to light grown ones and rosette leaves showed the characteristics of juvenile leaves (Wu et al. 2009; data not shown).

\section{Rooting}

The rooting response of Arabidopsis hypocotyls after increasing periods of exposure to light is presented in Fig. 1a. The highest rooting response $(100 \%, 5.6$ roots per explant) occurred when the seedlings had been kept for 12 days in darkness. The increased capability to root was also evident from the speed of root emergence from the hypocotyl (7 vs. 9 days after explant excision, data not shown). Increase of the number of days with light reduced rooting and the lowest rooting response (2.8 roots per explant) was observed in hypocotyl segments excised from seedlings that had grown 12 days in light. In five different light-dark conditions, no difference was observed in rooting percentage $(100 \%)$.

Similar to dark-grown hypocotyl, segments excised from FSs of etiolated donor plants regenerated more roots per explant ( 23 vs.10, $P<0.05)$. The percentage of rooted explants was also higher but the difference was not significant ( 90 vs. $75 \%, P=0.16$ ) (Fig. 1b).

\section{Gene expression in control and etiolated hypocotyl explants}

We were interested to see if the better rooting response of etiolated seedlings is because of change in auxin signaling. In addition, abundance of lateral shoots in dark-grown seedlings might be related to the change in SL biosynthesis or signaling and this could influence AR formation. Therefore, the expression of SL biosynthesis and signaling genes (MAX1, MAX2, MAX3, and MAX4) as well as auxin signaling related genes (TIR1, $A F B 1$ and $A F B 2$ ), was analyzed by qRT-PCR. ARFs were excluded from this study as changes in their expression by light have been addressed previously (Gutierrez et al. 2009). All genes showed up-regulation in the light. Highest up-regulation was observed in MAXI and TIRI ( $\geq$ threefold) followed by nearly twofold up-regulation 


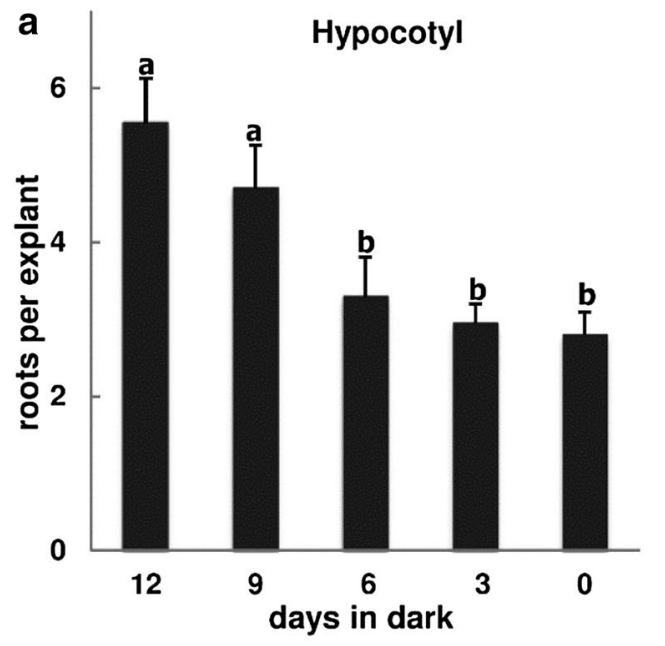

Flower stem

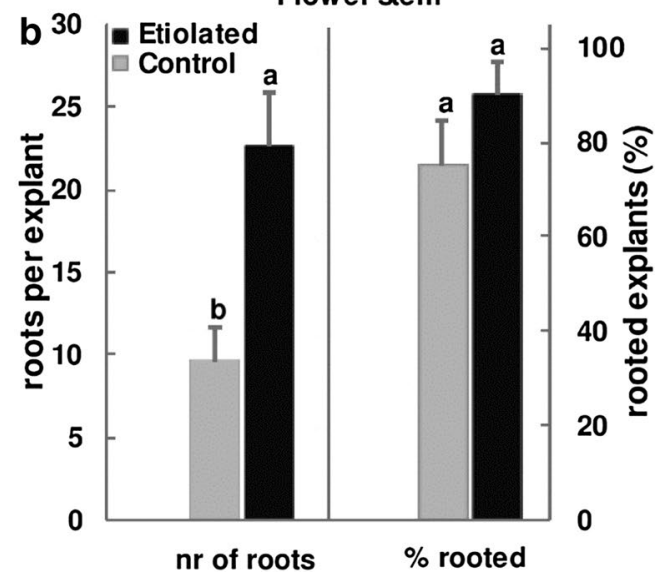

Fig. 1 Rooting of Arabidopsis explants after an etiolation pre-treatment. a Rooting at $10 \mu \mathrm{M}$ IBA of hypocotyl explants after increasing periods of exposure to light. Different letters represent means that are significantly different at $P<0.05$. b Rooting at $30 \mu \mathrm{M}$ IAA of FS segments grown in darkness or light for 12 weeks. Different letters represent differences that are significant at $P<0.05$. Means across replicates are presented with SE. Note that different scales are used in $\mathbf{a}$ and $\mathbf{b}$

in $M A X 4, M A X 3$ and $M A X 2$ (Fig. 2). The up-regulation of $A F B 1$ and $A F B 2$ genes were less pronounced (1.4 and 1.6-fold).

\section{Level of soluble sugars in hypocotyls of control} and etiolated donor plants

A major determinant of the capability to root is the ontogenetic state (juvenile tissues root better than adult ones) which is closely related with the endogenous sucrose level. Therefore, to see if change in the rooting response of hypocotyl explants upon etiolation is related to the change in ontogenetic stage, we determined the level of soluble sugars in the hypocotyls of light grown

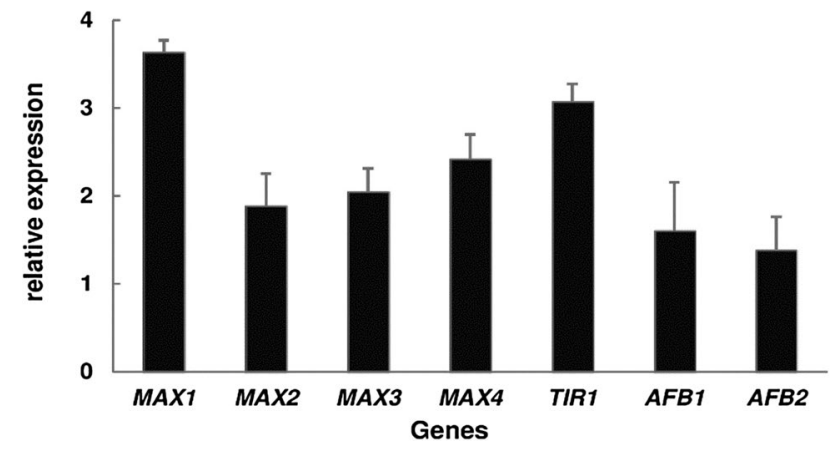

Fig. 2 Expression of SL biosynthesis and signaling genes as well as auxin response genes, comparing hypocotyls of light grown vs. those of etiolated seedlings. Total RNA was extracted from complete seedlings 12 days after germination and seedling growth in two different light conditions ( 12 days dark vs. 12 days light). Relative expression levels of indicated genes were quantified by qRT-PCR and normalized to Act 2 levels. Each value is the mean \pm SE of three biological and three technical replicates and presents the ratio of expression in the light divided by expression in the dark

and etiolated seedlings (Fig. 3). Etiolation significantly $(P<0.05)$ decreased the level of soluble sugars.

\section{The effect of flooding on AR formation}

\section{Morphology and anatomy}

Major morphological differences were observed between flooding-treated and control plants. Flooded plants were more robust (Fig. 4). The stem was thicker, the leaves (both rosette and aerial) were larger and instead of a

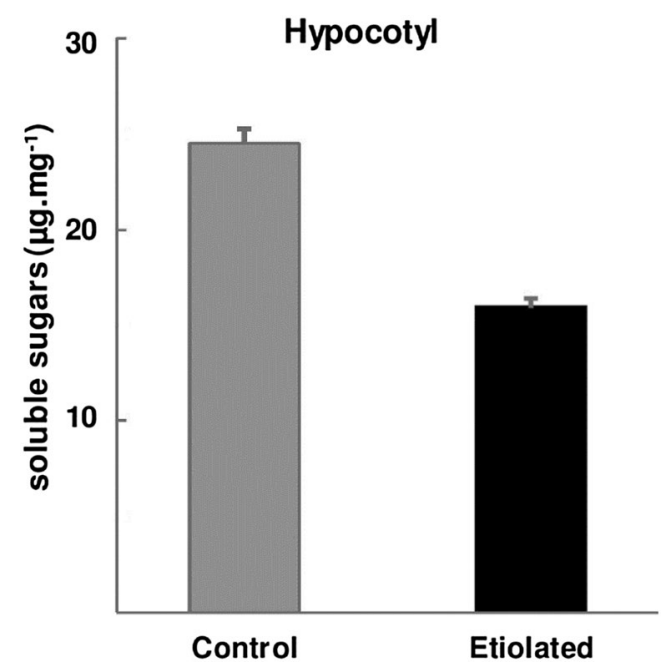

Fig. 3 The level of soluble sugars in hypocotyl segments excised from seedlings grown for 12 days in the dark (etiolated) or in the light (control). Means across replicates are presented with SE 

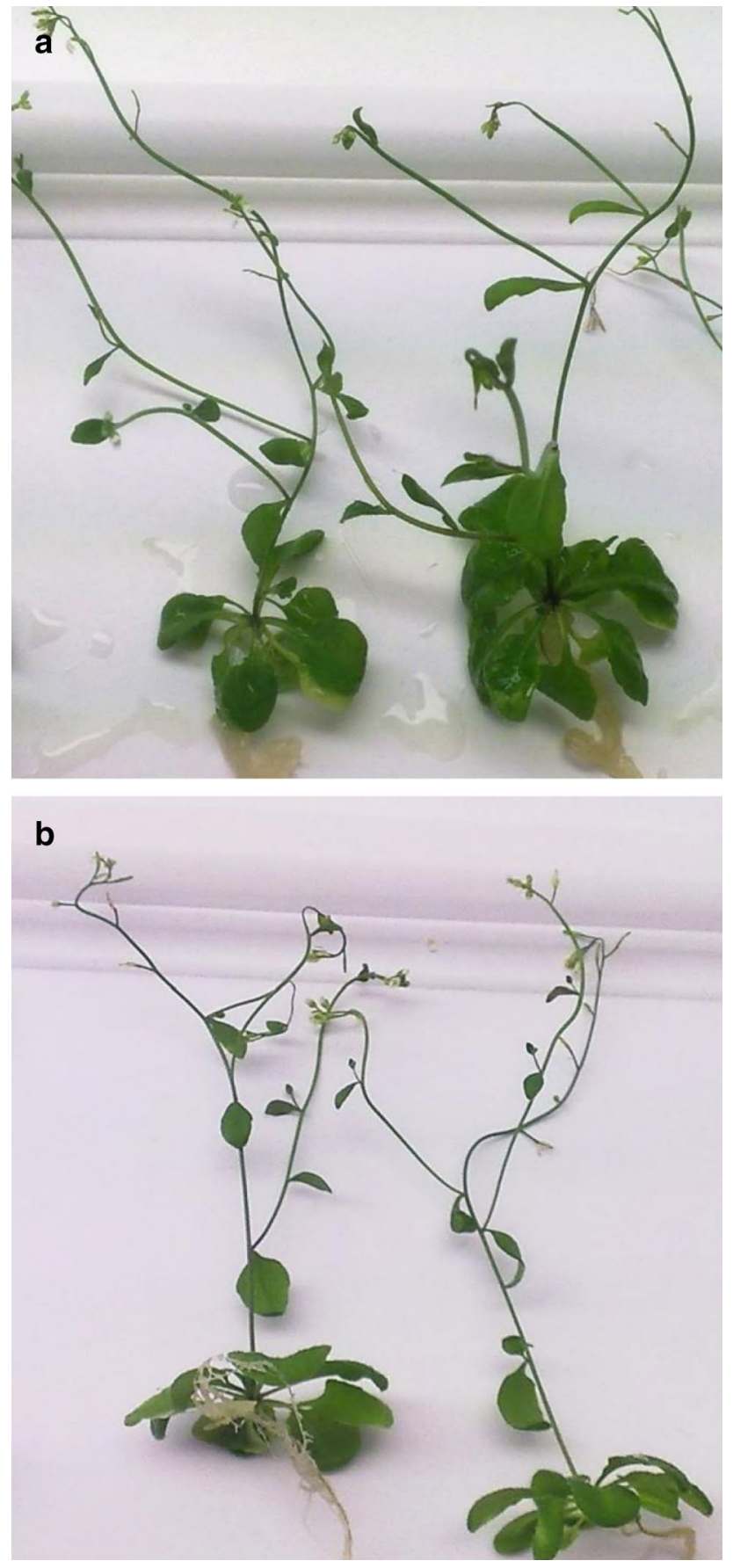

Fig. 4 Flooded (a) and control (nontreated) (b) Arabidopsis plants. Flooding had been for one week

single FS, flooded donor plants did generate more FSs $(\sim 2-3)$.

In order to get better insight about the higher rooting response of explants taken from flooded donor plants, we carried out a microscopic analysis of excised FS segments just before the start of the rooting treatment. Results are shown in Fig. 5. The obvious difference is the larger diameter of cross sections of flooded stems (nearly twice). Comparing the cross section of FS explants taken from flooding-treated (Fig. 5d, e) and control (Fig. 5a, b) donor plants points to the formation of secondary phloem in FS of flooded plants (arrow head in Fig. 5d, e).

\section{Rooting}

The rooting response of explants excised from hypocotyl and FS after one-week flooding is shown in Fig. 6. Hypocotyls excised from flooded seedlings produced significantly more roots (4.8 vs. $2.4, P<0.05$ ) (Fig. 6a). Furthermore, rooting started earlier (6 vs. 9 days after explant excision, data not shown). Flooding of donor plants increased rooting of FS explants significantly $(P<0.05)$ (Fig. 6b).

\section{Level of soluble sugars in FS of control and flooded donor plants}

We also measured the level of soluble sugars in FS explants at the start of rooting treatment just after the flooding treatment. The results showed that the level of soluble sugars in FSs of flooded plants was significantly (7.7 vs. $\left.12.58 \mu \mathrm{g} \mathrm{mg}^{-1}, P<0.05\right)$ lower than in the FS of nontreated plants (Fig. 7).

\section{Discussion}

Adventitious rooting is an essential, inevitable step in vegetative propagation. The failure of cuttings to regenerate roots is a main problem in horticulture. There are two major pathways to improve rooting. The first is to improve the rooting process itself. In this approach, all hormones and all different auxins have been examined in many publications. Unfortunately, no substantial progress has been made and the treatment with auxin developed by Thimann and Went (1934) in the 1930s remains the best option. The second pathway is to improve rootability of the cuttings. This approach involves pre-treatments of donor plants from which the cuttings are taken and has received less attention in rooting research. Three pre-treatments have emerged, namely, rejuvenation, etiolation and flooding. We have initiated research on these methods in Arabidopsis to unravel the underlying mechanisms. In Arabidopsis, rejuvenation strongly enhances the capability to root (Massoumi et al. 2017). In the present paper, we investigate etiolation and flooding.

\section{Etiolation}

Rooting of both hypocotyl and FS segments excised from etiolated donor plants was strongly enhanced compared to 
a
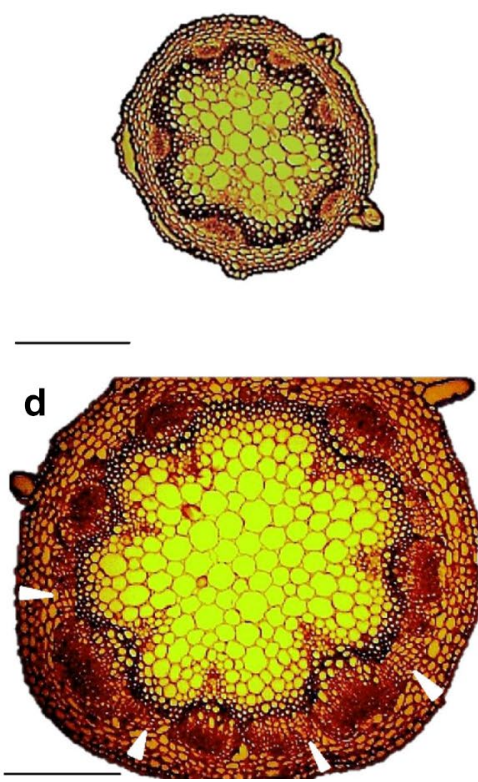

b
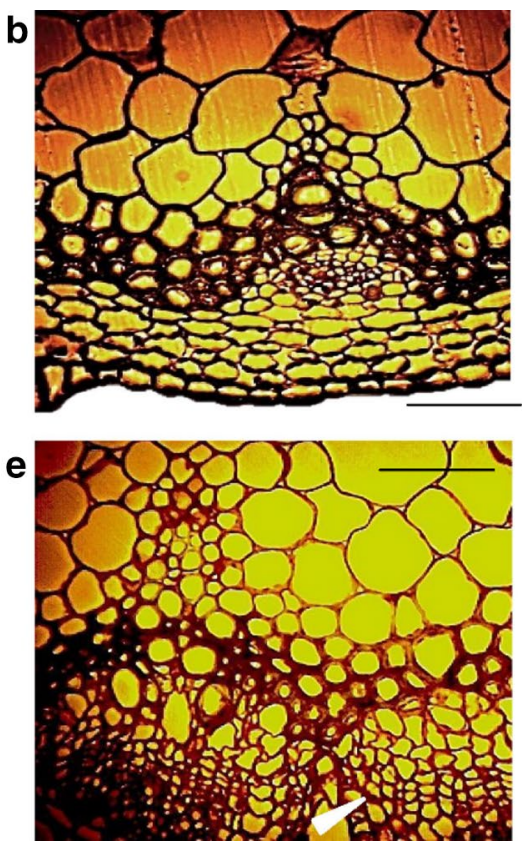

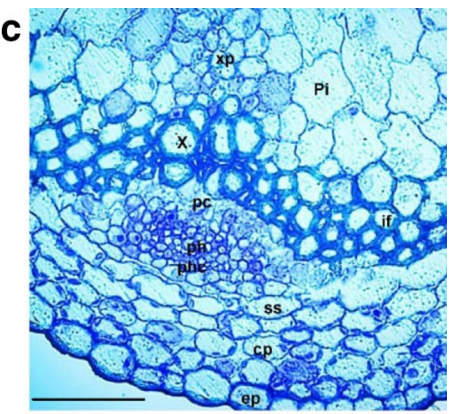

Fig. 5 Anatomy of flooding-treated (d, e) and nontreated (a, b) Arabidopsis FSs. The duration of the flooding treatment had been 1 week. Different cell layers in the FS are illustrated in c. Arrow heads point the secondary phloem in $\mathbf{d}$ and e. Scale bar is $1 \mathrm{~mm}$ in a and d, and $50 \mu \mathrm{m}$ in b and e. Cortical parenchyma (cp), epidermis (ep), interfascicular fibers (if), procambium (pc), phloem (ph), phloem cap (phc), pith (pi), protoxylem (px), root primordia (rp), starch sheath (ss), xylem (x), xylem parenchyma (xp) control donor plants (Fig. 1). In the hypocotyls of etiolated seedlings (12 and 9 days dark) root initials even occurred at the time of explant excision, whereas no initials had been formed in hypocotyls of nontreated seedlings. Correspondingly, Klopotek et al. (2010) reported that in petunia cuttings root meristem formation had already started during the dark treatment and was enhanced during the rooting period.

Why is rooting enhanced in etiolated stem tissues? We report here two possible causes. First, improved rooting may be related to increased auxin transport. We observed that in etiolated seedlings apical dominance is reduced. The abundance of lateral shoots in dark-grown plants resembles the response of max (more axillary growth) mutants. These mutants are characterized by increased outgrowth of axillary buds caused by a defect in SL synthesis (Stirnberg et al. 2002) and by increased AR formation (Rasmussen et al. 2012b). In Arabidopsis, it has been shown that increased auxin transport brought about by mutation of the MAX genes leads to increased branching (Bennett et al. 2006). In these mutants, the synthesis of SL is greatly diminished. This indicates that $\mathrm{SL}$ is an inhibitor of polar auxin transport. It has been reported that when SL is reduced by the carotenoid biosynthesis inhibitor, fluridone, rooting is also increased (Rasmussen et al. 2012a; Massoumi, unp. results). We showed in this paper that in the light the expression of SL biosynthesis (MAX1, MAX3 and MAX4) and signaling (MAX2) genes is increased (Fig. 2). High synthesis of SL in the light will decrease auxin transport and reduce rooting. Similarly, Koltai et al. (2011) have shown that intensity of light is a positive regulator of SL levels in tomato roots.

Although we observed increased rooting response by etiolation, up-regulation of TIRI by light seems to be in conflict with this as an increase in its expression may result in more auxin signaling, activation of downstream pathways and consequently formation of more roots. However, it is not always the case and the involvement of other regulatory mechanisms, e.g., post-transcriptional regulation of TIR/AFBs which restrict their spatial protein expression levels should also be taken into account. We did observe that in etiolated hypocotyls root formation had already been started at the time of explant excision. This may indicate that in the dark, cells become competent and root initials are formed. Probably from this stage onward, root initials just need an external signal for further growth. If this is true, the up-regulation of $T I R I$ in the light is then justified. Gutierrez et al. (2009) have also found that ARF6 and 8, positive regulators of AR formation, are positively regulated by light.

There is a second possible mechanism for the better rooting response of explants taken from etiolated seedlings. 

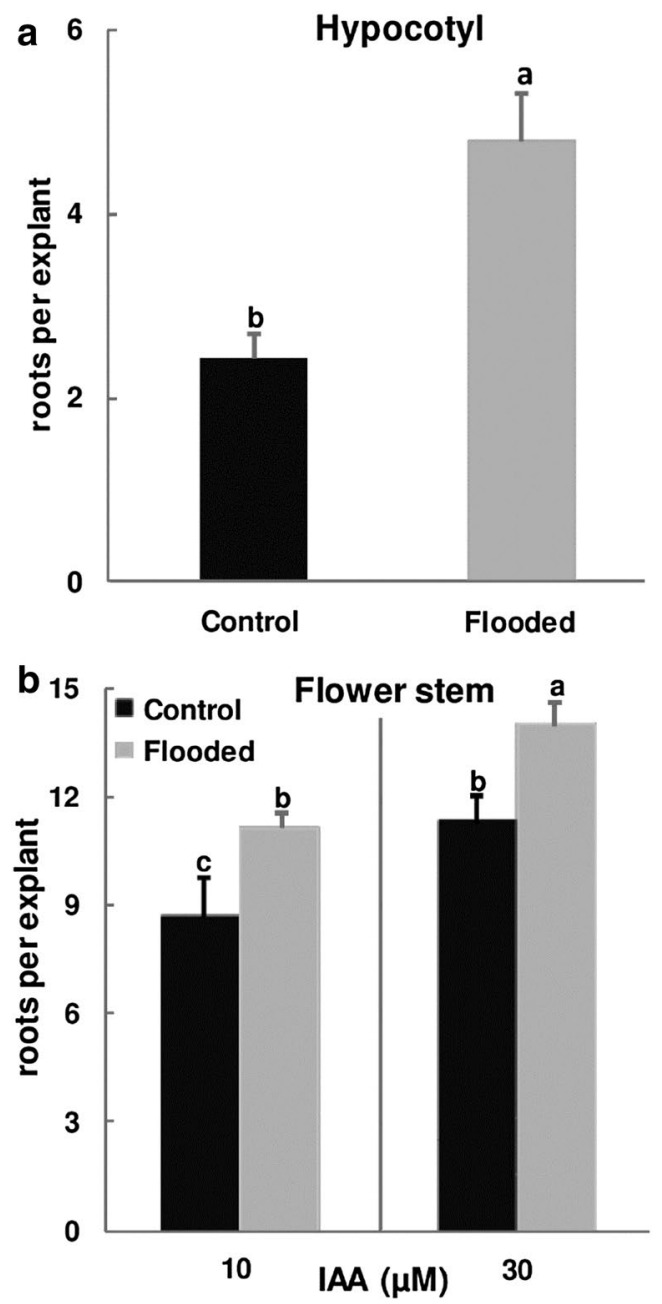

Fig. 6 The rooting response of two Arabidopsis explants after oneweek treatment of seedlings/donor plants with flooding. a Rooting of hypocotyls at $10 \mu \mathrm{M}$ IBA. Different letters represent means that are significantly different at $P<0.05$. b Rooting of FSs at IAA (10 and $30 \mu \mathrm{M})$. Different letters represent means that are significantly different at $P<0.05$. Means across replicates are presented with SE. Note that different scales are used in $\mathbf{a}$ and $\mathbf{b}$

AR formation is known as a high-energy demanding process. Carbohydrates are the principle source of energy and structural elements. Indeed, a reduction of sucrose during the rooting treatment leads to a reduction of rooting (De Klerk and Calamar 2002). Here, we observed a negative influence of etiolation on the level of soluble sugars possibly caused by the absence of photosynthesis and/or by the extra use of carbohydrates as building blocks for stem elongation. So if etiolation has an effect via sucrose levels, at first sight a reduction of rooting would be expected since AR formation also requires energy and building blocks. In etiolated tissues, though, an increase of rooting occurred. This may be related to the role of sucrose as a signaling molecule (Smeekens 2000; Price et al. 2004). Wu and Poethig (2006) showed that phase transition from juvenile to

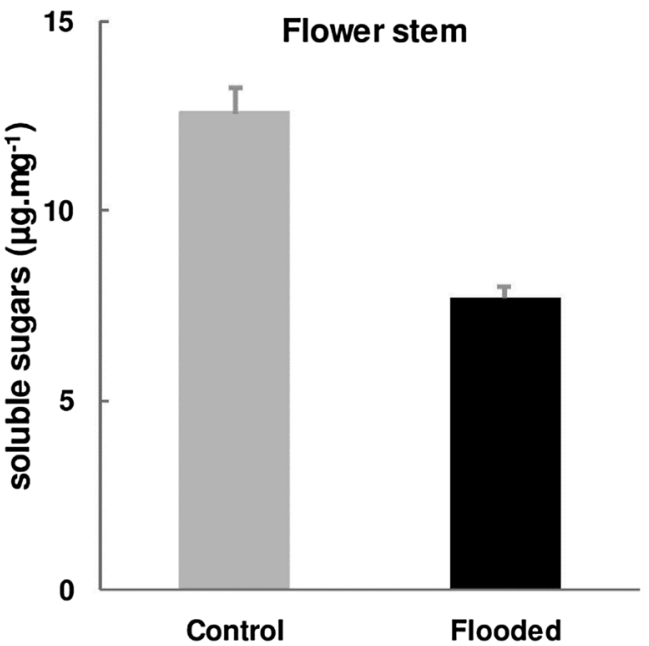

Fig. 7 The level of soluble sugars in FS explants taken from flooded and control (nontreated) plants. Means across replicates are presented with SE

mature is stimulated by a high endogenous sucrose level. This seems to be a general mechanism as the same was found in lily (Langens-Gerrits et al. 2003). In the juvenile phase, miR 156 is highly expressed and its expression decreases dramatically during vegetative phase change (Wu and Poethig 2006). It has also been shown that supplying Arabidopsis plant with sugar reduces the level of miR156 while sugar deprivation increases miR156 expression. Removing leaves and reduced photosynthesis also lead to increased miR156 level and consequently delays the juvenile-to-adult transition (Yang et al. 2013). Considering these facts and the findings of Massoumi et al. (2017) indicating that maturation related loss in AR formation is under the influence of miR156, an additional role for sugar in increasing AR formation can be hypothesized. We speculate here that reduced carbohydrate content during dark exposure increases the level of miR156 leading to rejuvenation of donor plants and consequently to increased $A R$ formation potential.

\section{Flooding pre-treatment of donor plants}

We also applied flooding as a pre-treatment of donor plants. The plantlets were cultured on a double layer: a layer of liquid MS medium of ca. 6-7 mm was added on top of the semi-solid medium. It first should be noted that the growth was much enhanced as is usually observed for double layer. To the best of our knowledge, ex vitro flooding decreases growth (e.g., Maurenza et al. 2012). The enhancement of growth in vitro is probably related to better nutrient uptake from liquid medium than from semi-solid medium.

In addition to morphological changes, a flooding pre-treatment increased the rooting response of excised 
hypocotyl and FS segments. This was evident at the time of explant excision (prior to rooting treatment) when some of the flooded hypocotyls had already started rooting. This was similar to etiolated hypocotyls that had produced root initials at the time of explant excision. Vidoz et al. (2010) reported that $24 \mathrm{~h}$ after submergence of tomato plants, the root primordia had already formed and by $48 \mathrm{~h}$ they had reached the epidermis layer. In control plants, however, no emerged ARs were observed even after 7 days. The replacement of the original root system with ARs from the stems in flooded plants has also been observed in other species such as Rumex palustris Sm. (Visser et al. 1996), deepwater rice (Mergemann and Sauter 2000), the perennial wetland species Cotula coronopifolia and Meionectes brownii (Rich et al. 2012) and in Larix laricina (tamarack) (Calvo-Polanco et al. 2012). Thus, initiating organogenesis to replace the original root system with ARs seems to be an adaptive response to the stress situation and is related to ethylene accumulation in the stem (Visser et al. 1996).

To get a better understanding about the higher rooting response of explants taken from flooded donor plants, we performed a microscopic analysis in FS explants. The anatomical structure of Arabidopsis FS has been addressed previously (Welander et al. 2014). The FS consists of one row of epidermis cells as outermost layer and a few rows of cortex cells. The innermost cortical cell layer has been reported as a starch sheath. In the center of the FS interfascicular tissues, phloem and xylem occur which are separated by procambial cells. Protoxylem with parenchyma constitutes the innermost part of the vascular bundle (Fig. 5c). We observed that in flooded donor plants FS has a larger diameter of cross sections (nearly twice) that is mainly related to the formation of secondary phloem. Does this change at anatomical level influence adventitious rooting? Welander et al. (2014) showed that in FS explants starch sheath cells adjacent to the phloem are the main origins of ARs. It seems, therefore, that the formation of secondary phloem in flooded explants increases the area in which starch sheath cells are adjacent to the phloem parts. This consequently increases the chances of root initials being formed.

In addition to microscopic analysis, our study showed that the level of soluble sugars is negatively influenced by flooding. Just as in the etiolation pre-treatment, this may stimulate the capacity to root by promoting the juvenile state.

\section{Conclusion}

AR formation is influenced by numerous environmental and endogenous factors. In this study, we studied the effect of two donor plant pre-treatments, flooding and etiolation, on subsequent in vitro rooting of Arabidopsis tissues (hypocotyl and FS explants). Our results showed that these two pre-treatments can be used as efficient ways to increase AR formation. We provided further indications of how environmental conditions may affect the physiological and biochemical condition of donor plants so that rooting is promoted. These factors may be suitable for use in commercial micropropagation.

Author contribution $\mathrm{MM}$ and GD conceived and designed research. GD, FK and RV supervised the research. MM conducted experiments and wrote the manuscript. All authors read and approved the manuscript.

\section{Compliance with ethical standards}

Conflict of interest The authors declare that they have no conflict of interest.

Open Access This article is distributed under the terms of the Creative Commons Attribution 4.0 International License (http:// creativecommons.org/licenses/by/4.0/), which permits unrestricted use, distribution, and reproduction in any medium, provided you give appropriate credit to the original author(s) and the source, provide a link to the Creative Commons license, and indicate if changes were made.

\section{References}

Agulló-Antón MA, Sánchez-Bravo J, Acosta M, Druege U (2011) Auxins or sugars: what makes the difference in the adventitious rooting of stored carnation cuttings? J Plant Growth Regul 30:100-113

Bennett T, Sieberer T, Willett B, Booker J, Luschnig C, Leyser O (2006) The Arabidopsis MAX pathway controls shoot branching by regulating auxin transport. Curr Biol 16:553-563

Bramley H, Turner NC, Turner DW, Tyerman SD (2010) The contrasting influence of short-term hypoxia on the hydraulic properties of cells and roots of wheat and lupin. Funct Plant Biol 37:183-193

Calvo-Polanco M, Señorans J, Zwiazek JJ (2012) Role of adventitious roots in water relations of tamarack (Larix laricina) seedlings exposed to flooding. BMC Plant Biol 12:99

Colmer T, Voesenek L (2009) Flooding tolerance: suites of plant traits in variable environments. Funct Plant Biol 36:665-681

Daud N, Faizal A, Geelen D (2013) Adventitious rooting of Jatropha curcas $\mathrm{L}$. is stimulated by phloroglucinol and by red LED light. In Vitro Cell Dev Biol Plant 49:183-190

De Klerk GJ (2002) Rooting of microcuttings. In: Waisel Y, Eshel A, Kafkaki U (eds) Plant Roots: the hidden half. Marcel Dekker, New York, pp 349-357

De Klerk GJ, Calamar A (2002) Effect of sucrose on adventitious root regeneration in apple. Plant Cell Tiss Org Cult 70:207-212

De Klerk G, Ter Brugge J, Smulders R, Benschop M (1989) Basic peroxidases and rooting in microcuttings of Malus. In: I International Symposium on In Vitro Culture and Horticultural Breeding 280, pp 29-36

De Klerk GJ, Paffen A, Jasik J, Haralampieva V (1999a) A dual effect of ethylene during rooting of apple microcuttings. In: Altman A, Ziv M, Izhar S (eds) Plant biotechnology and in vitro biology in the 21st century. Kluwer Academic Press, Dordrecht, pp 41-44 
De Klerk G-J, Van der Krieken W, De Jong JC (1999b) Review: the formation of adventitious roots: new concepts, new possibilities. In Vitro Cell Dev Biol Plant 35:189-199

Ding Z, Galván-Ampudia CS, Demarsy E, Langowski L, Kleine-Vehn J, Fan Y et al (2011) Light-mediated polarization of the PIN3 auxin transporter for the phototropic response in Arabidopsis. Nat Cell Biol 13:447-452

Dos Santos Maraschin F, Memelink J, Offringa R (2009) Auxininduced, SCF(TIR1)-mediated polyubiquitination marks AUX/ IAA proteins for degradation. Plant J 59:100-109

Fett-Neto AG, Fett JP, Goulart LWV, Pasquali G, Termignoni RR, Ferreira AG (2001) Distinct effects of auxin and light on adventitious root development in Eucalyptus saligna and Eucalyptus globulus. Tree Physiol 21:457-464

Gray WM, Kepinski S, Rouse D, Leyser O, Estelle M (2001) Auxin regulates SCF(TIR1)-dependent degradation of AUX/IAA proteins. Nature 414:271-276

Gutierrez L, Bussell JD, Pacurar DI, Schwambach J, Pacurar M, Bellini C (2009) Phenotypic plasticity of adventitious rooting in Arabidopsis is controlled by complex regulation of auxin response factor transcripts and microRNA abundance. Plant Cell 21:3119-3132

Haissig BE, Davis TD (1994) A historical evaluation of adventitious rooting research to 1993. In: Biology of adventitious root formation. In: Davis TC, Hassig BE (eds) Biology of adventitious root formation. Plenum Press, New York, pp 275-331

Hammerschlag FA, Bauchan GR, Scorza R (1987) Factors influencing in vitro multiplication and rooting of peach cultivars. Plant Cell Tissue Organ Cult 8:235-242

Hartmann HT, Kester DE, Davies FT, Geneve RL (2011) Hartmann and Kester's plant propagation principles and practices, 8th edn. Prentice Hall, Boston

Jackson MB (1985) Ethylene and responses of plants to soil waterlogging and submergence. Annu Rev Plant Physiol 36:145-174

Klopotek Y, Haensch KT, Hause B, Hajirezaei MR, Druege U (2010) Dark exposure of petunia cuttings strongly improves adventitious root formation and enhances carbohydrate availability during rooting in the light. J Plant Physiol 167:547-554

Koltai H, Cohen M, Chesin O, Mayzlish-Gati E, Becard G, Puech V et al (2011) Light is a positive regulator of strigolactone levels in tomato roots. J Plant Physiol 168:1993-1996

Koukourikou-Petridou MA (1998) Etiolation of donor plants affects adventitious root formation and hormone content of pea stem cuttings. Plant Growth Regul 25:17-21

Langens-Gerrits M, De Klerk GJ, Croes A (2003) Phase change in lily bulblets regenerated in vitro. Physiol Plant 119:590-597

Livak KJ, Schmittgen TD (2001) Analysis of relative gene expression data using real-time quantitative PCR and the 2(-Delta Delta C(T)) method. Methods 25:402-408

Maene L, Debergh P (1985) Liquid medium additions to established tissue cultures to improve elongation and rooting in vivo. Plant Cell Tiss Org Cult 5:23-33

Massoumi M, De Klerk GJ (2013) Adventitious root formation in Arabidopsis thaliana: development of a model system. Acta Hortic 988:99-105

Massoumi M, Krens FA, Visser RGF, De Klerk GJM (2017) Azacytidine and miR156 promote rooting in adult but not in juvenile Arabidopsis tissues. J Plant Physiol 208:52-60

Maurenza D, Marenco RA, Parolin P, Piedade MTF (2012) Physiological responses to flooding and light in two tree species native to the Amazonian floodplains. Aquat Bot 96:7-13

Maynard BK, Bassuk NL (1988) Etiolation and banding effects on adventitious root formation. In: Davis TD, Haissig BE, Sankhla $\mathrm{N}$ (eds) Adventitious root formation in cuttings. Dioscorides Press, Portland, pp 29-46
Mergemann H, Sauter M (2000) Ethylene induces epidermal cell death at the site of adventitious root emergence in rice. Plant Physiol 124:609-614

Murashige T, Skoog F (1962) A revised medium for rapid growth and bio assays with tobacco tissue cultures. Physiol Plant 15:473-497

Normanly J, Slovin JP, Cohen JD (2004) B1. Auxin biosynthesis and metabolism. In: Davies PJ (ed) Plant hormones: biosynthesis, signal transduction, action. Kluwer Academic Publishers, Dordrecht, pp 36-62

Petroski MD, Deshaies RJ (2005) Function and regulation of cullinRING ubiquitin ligases. Nat Rev Mol Cell Biol 6:9-20

Price J, Laxmi SA, Martin SK, Jang JC (2004) Global transcription profiling reveals multiple sugar signal transduction mechanisms in Arabidopsis. Plant Cell 16:2128-2150

Rasmussen A, Beveridge CA, Geelen D (2012a) Inhibition of strigolactones promotes adventitious root formation. Plant Signal Behav 7:694-697

Rasmussen A, Mason MG, De Cuyper C, Brewer PB, Herold S, Agusti J et al (2012b) Strigolactones suppress adventitious rooting in Arabidopsis and pea. Plant Physiol 158:1976-1987

Rich SM, Ludwig M, Colmer TD (2012) Aquatic adventitious root development in partially and completely submerged wetland plants Cotula coronopifolia and Meionectes brownii. Ann Bot 110:405-414

Sassi M, Lu Y, Zhang Y, Wang J, Dhonukshe P, Blilou I et al (2012) COP1 mediates the coordination of root and shoot growth by light through modulation of PIN1-and PIN2-dependent auxin transport in Arabidopsis. Development 139:3402-3412

Shi X, Brewbaker JL (2006) Vegetative propagation of Leucaena hybrids by cuttings. Agroforestry Syst 66:77-83

Shibuya T, Tsukuda S, Tokuda A, Shiozaki S, Endo R, Kitaya Y (2013) Effects of warming basal ends of Carolina poplar (Popиlus $\times$ canadensis Moench.) softwood cuttings at controlled lowair-temperature on their root growth and leaf damage after planting. J Forest Res 18:279-284

Shibuya T, Taniguchi T, Tsukuda S, Shiozaki S, Itagaki K (2014) Adventitious root formation of Japanese cedar (Cryptomeria japonica D. Don) cuttings is stimulated by soaking basal portion of cuttings in warmed water while cooling their apical portion. New Forest 45:589-602

Smeekens S (2000) Sugar-induced signal transduction in plants. Annu Rev Plant Physiol Plant Mol Biol 5:49-81

Sorin C, Bussell JD, Camus I, Ljung K, Kowalczyk M, Geiss G et al (2005) Auxin and light control of adventitious rooting in Arabidopsis require ARGONAUTE1. Plant Cell 17:1343-1359

Stirnberg P, Van de Sande K, Leyser HO (2002) MAX1 and MAX2 control shoot lateral branching in Arabidopsis. Development 129:1131-1141

Symons GM, Reid JB (2003) Interactions between light and plant hormones during de-etiolation. J Plant Growth Regul 22:3-14

Thimann KV, Went FW (1934) On the chemical nature of the root forming hormone. Proc Konink Akad Wetensch (Amsterdam) 37:456-459

Vidoz ML, Loreti E, Mensuali A, Alpi A, Perata P (2010) Hormonal interplay during adventitious root formation in flooded tomato plants. Plant J 63:551-562

Visser EJ, Cohen JD, Barendse GW, Blom CW, Voesenek LA (1996) An ethylene-mediated increase in sensitivity to auxin induces adventitious root formation in flooded Rumex palustris Sm. Plant Physiol 112:1687-1692

Voesenek LACJ, Sasidharan R (2013) Ethylene- and oxygen signalling- drive plant survival during flooding. Plant Biol 15:426-435

Welander M, Geier T, Smolka A, Ahlman A, Fan J, Zhu L-H (2014) Origin, timing, and gene expression profile of adventitious rooting in Arabidopsis hypocotyls and stems. Am J Bot 101:255-266 
Wu G, Poethig RS (2006) Temporal regulation of shoot development in Arabidopsis thaliana by miR156 and its target SPL3. Development 133:3539-3547

Wu G, Park MY, Conway SR, Wang J-W, Weigel D, Poethig RS (2009) The sequential action of miR156 and miR172 regulates developmental timing in Arabidopsis. Cell 138:750-759

Wynne J, McDonald M (2002) Adventitious root formation in woody plant tissue: influence of light and indole-3-butiricacid (IBA) on adventitious root induction in Betula pendula. In Vitro Cell Dev Biol Plant 38:210-212
Yang L, Xu M, Koo Y, He J, Poethig RS (2013) Sugar promotes vegetative phase change in Arabidopsis thaliana by repressing the expression of MIR156A and MIR156C. Elife 2:e00260

Yemm E, Willis A (1954) The estimation of carbohydrates in plant extracts by anthrone. Biochem J 57:508-514

Zhou J, Qi A-G, Zhang Y-C, Wan S-W, Qin P (2012) Adventitious root growth and relative physiological responses to waterlogging in the seedlings of seashore mallow (Kosteletzkya virginica), a biodiesel plant. Aust J Crop Sci 6:73-80 